\title{
A novel approach to frequency control in an islanded microgrid by load shedding scheduling
}

\author{
M. Kohansal, M. J. Sanjari, G. B. Gharehpetian \\ Electrical Engineering Department, Amirkabir University of Technology, Tehran. Iran \\ Phone/Fax number: +0098-21-64543504, \\ E-mail: mh.kohansal@gmail.com, m_j_sanjari@aut.ac.ir, grptian@aut.ac.ir
}

\begin{abstract}
A microgrid is composed of distributed power generation systems (DGs), distributed energy storage devices (DSs), and loads. To maintain a specific frequency in the island mode as an important requirement, the control of DGs output and charge action of DGs are used in supply surplus conditions and load-shedding and discharge action of DGs are used in supply shortage conditions. Recently, multiagent systems (MAS) for autonomous microgrid operation have been studied. Especially, load-shedding, which is intentional reduction of electricity use, is a critical problem in islanded microgrid operation based on the MAS. Therefore, effective schemes for load-shedding are required. A novel optimization algorithm called ICA has been used to optimize this load shedding procedure.
\end{abstract}

\section{Key words}

Microgrid, Load Shedding, Multi-Agent system (MAS), frequency stability

\section{Introduction}

The interconnection of small modular generation system such as photovoltaic (PV), fuel cells, micro turbines (MT), small wind turbines (WT) and storage devices (Fly wheels, super capacitors, batteries,...) to LV distribution system, as shown in Fig.1, will lead to a new energy system paradigm, usually referred as the Microgrid (MG) [1]-[5]. Depending on the primary energy source used, the MS dimension and the type of power interface, they can be considered as noncontrollable, partially controllable (e.g. renewable sources that can reduce the power output only) and controllable (e.g. small co-generation units and storage units). A MG can be an extremely flexible cell of the electrical power system if properly controlled through management and control systems. Two different modes of operation can be envisaged [4]:

-Normal Interconnected Mode: the MG is connected to the medium voltage (MV) grid, being either partially supplied from it or injecting some amount of power into it;
-Emergency Mode: the MG operates autonomously when the disconnection from the upstream MV network occurs due to planned or unplanned events (e.g. maintenance actions or faults in the MV network, respectively).

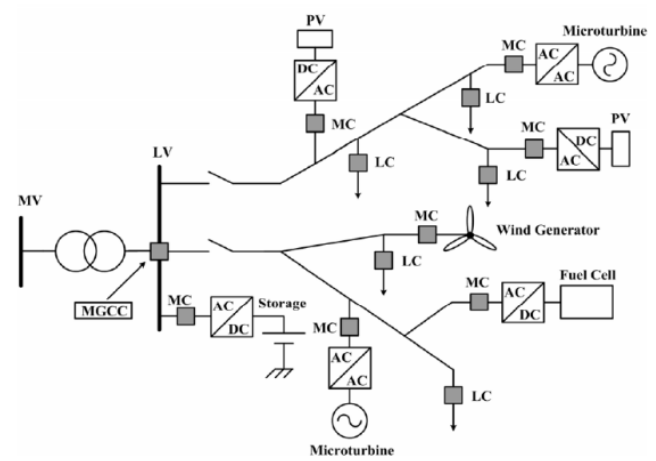

Fig.1. MG architecture, comprising MS, loads and control devices

The MG operation philosophy has been developed based on a hierarchical type control approach headed by the MG Central Controller (MGCC) [3]-[4]. However, frequency control problems arise during islanded operation due to the slow response of MS to control signals and due the inexistence of rotating masses directly connected to the grid (inertia less system). Sudden islanding of the MG due to faults occurring in the MV network may cause high unbalances between local load and generation which must be compensated by local MS and through a very efficient use of storage devices and load shedding mechanisms [4].

A critical security trait for MG operation is to ensure they can run into islanded operation following an unexpected event without collapse due to imbalance of loads and generations. Depending on the MG operating conditions, such as local load, local generation profile and MS availability for active power/frequency regulation, high amounts of power may be required to be injected or absorbed in the MG in the first moments subsequent to islanding. one of the normal method that is applied in a islanding $\mathrm{MG}$, 
is an efficient load shedding strategy in order to handle the problems resulting from limited storage capacity and from a generation deficient island.

In the above load shedding schemes, the load shedding signals are sent from MGCC to all the loads in MG. but these processes have delay because of the communication system inherent delay. Considering this fact, the central control of a MG cannot overcome the dynamic disturbances in a $\mathrm{MG}$ because of delaying. Moreover the communication links may face to the faults; hence the reliability of communicationbased control system is decreased.

Multiagent control systems have been presented better performance and faster response to the disturbances in a system [1] so in this paper a multiagent -based scheme for load shedding in a MG has been presented. The simulation results illustrate that this proposed distributed control systems presents a good performance.

To increase the performance of this control system, an optimization algorithm has been used to increase the performance of the controller.

\section{MG ARCHITECTURE}

\section{A. Microsource modeling}

In some papers the different microsources modeling have been presented [6]. The proposed models describe the behavior of the microsource accurately. In this paper a simple model for every microsource has been used. This simple model is in the exponential form as below:

$\mathrm{P}(\mathrm{t})=(\mathrm{A}+\mathrm{B} * \exp (-\mathrm{t} / \tau)) * \mathrm{u}(\mathrm{t})$

Where $\mathrm{P}(\mathrm{t})$ is the output active power of a microsource, $\mathrm{u}(\mathrm{t})$ is the step function and $\mathrm{A}, \mathrm{B}$ and $\tau$ are the parameters that are dependent on which microsource is modeled. So in response to a step changes in the microsource input, the microsource output changes exponentially.

\section{B. Inverter modeling}

Two kinds of control strategies may be used to operate an inverter [7]. The inverter model is derived according to the following control strategies.

- PQ inverter control: the inverter is used to supply a given active and reactive power set-point.

- Voltage source inverter (VSI) control: the inverter is controlled to "feed" the load with pre-defined values for voltage and frequency. Depending on the load, the VSI real and reactive power output is defined.

The VSI acts as a voltage source, with the magnitude and frequency of the output voltage controlled through droops (Fig.2), as described in the following equations:

$\mathrm{W}=\mathrm{w}_{0}-\mathrm{K}_{\mathrm{P}} * \mathrm{P}$

$\mathrm{V}=\mathrm{V}_{0}-\mathrm{K}_{\mathrm{Q}} * \mathrm{Q}$

Where $\mathrm{K}_{\mathrm{P}}$ and $\mathrm{K}_{\mathrm{Q}}$ are the droop slopes and $\mathrm{w}_{0}$ and $\mathrm{V}_{0}$ are the idle values for frequency and voltage at no loads and $\mathrm{P}$ and $\mathrm{Q}$ are output active and reactive power.

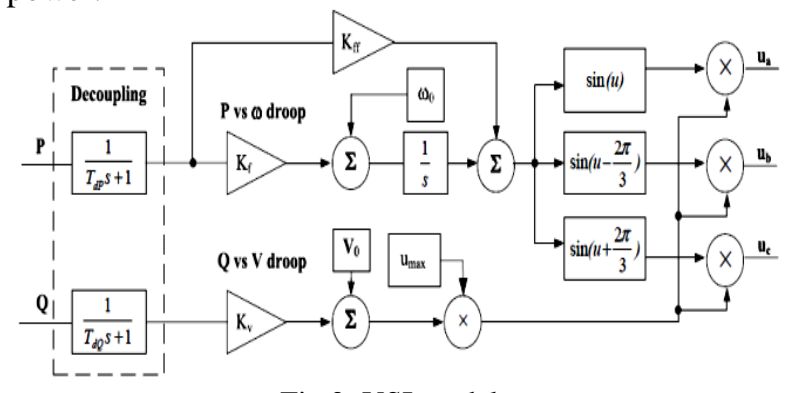

Fig.2: VSI model

\section{Imperialist Competitive Algorithm (ICA)}

Imperialist Competitive Algorithm is a new evolutionary optimization method which is inspired by imperialistic competition and has been applied in some different fields [8-12]. Like other evolutionary algorithms, it starts with an initial population which is called country and is divided into two types of colonies and imperialists which together form empires. Imperialistic competition among these empires forms the proposed evolutionary algorithm. During this competition, weak empires collapse and powerful ones take possession of their colonies. Imperialistic competition converges to a state in which there exists only one empire and colonies have the same cost function value as the imperialist.

After dividing all colonies among imperialists and creating the initial empires, these colonies start moving toward their relevant imperialist state which is based on assimilation policy. Fig.3 shows the movement of a colony towards the imperialist. In this movement, $\theta$ and $\mathrm{x}$ are random numbers with uniform distribution as illustrated in formula (1) and $d$ is the distance between colony and the imperialist.

$\mathrm{x} \sim \mathrm{U}(0, \beta \times \mathrm{d}), \theta \sim \mathrm{U}(-\gamma, \gamma)$

Where $\beta$ and $\gamma$ are parameters that modify the area that colonies randomly search around the imperialist. 


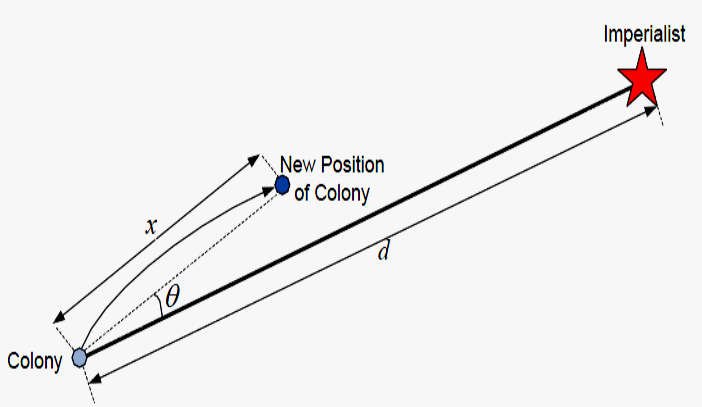

Fig.3: Motion of colonies toward their relevant imperialist

The total power of an empire depends on both the power of the imperialist country and the power of its colonies which is shown in formula (3).

T.C. $\cdot \mathrm{n}=\operatorname{Cost}\left(\right.$ imperialist $\left._{\mathrm{n}}\right)+\zeta *$ mean $\{\operatorname{Cost}($ colonies of impire $\left.\left._{n}\right)\right\}$

Fig.4 shows a big picture of the modeled imperialistic competition. Based on their total power, in this competition, each of the empires will have a likelihood of taking possession of the mentioned colonies. The more powerful an empire, the more likely it will possess the colonies. In other words these colonies will not be certainly possessed by the most powerful empires, but these empires will be more likely to possess them. Any empire that is not able to succeed in imperialist competition and cannot increase its power (or at least prevent decreasing its power) will be eliminated.

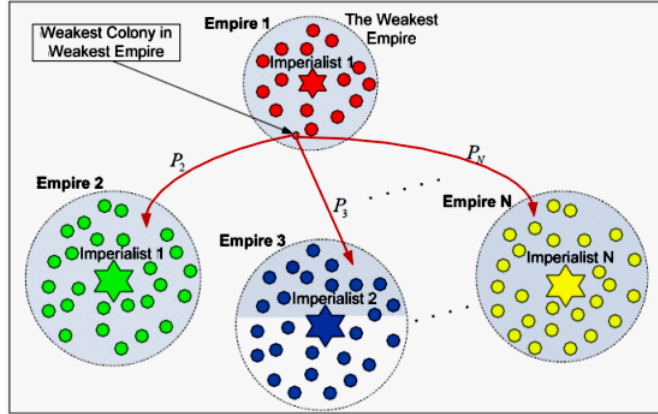

Fig.4. Imperialistic competition

\section{Simulation Results}

The proposed method is applied on the micro grid network (Fig.5) that loads and sources specifications in the worst operation condition are listed in table 1 . With these values, the frequency deviation is the most.

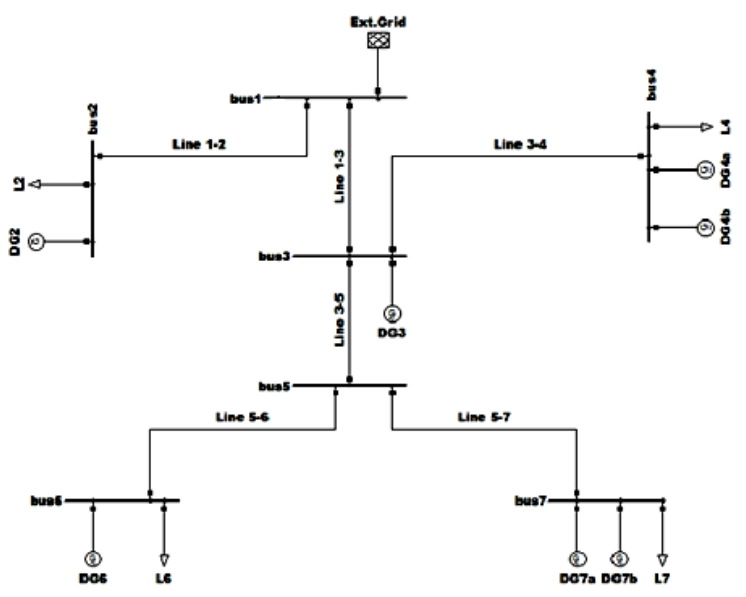

Fig.5: the network schematic

table.1: power of DGs and loads

\begin{tabular}{|c|c|}
\hline Sources and loads & $\mathrm{P}(\mathrm{kW})$ \\
\hline DG2 & 30 \\
\hline DG4a & 15 \\
\hline DG4b & 10 \\
\hline DG6 & 5 \\
\hline DG7a & 10 \\
\hline DG7b & 5 \\
\hline Load2(L2) & 60 \\
\hline Load4(L4) & 30 \\
\hline Load6(L6) & 25 \\
\hline Load7(L7) & 20 \\
\hline Ext.Grid & 60 \\
\hline
\end{tabular}

The cost function that is defined as below and is minimized by the ICA:

Cost function $=\int_{0}^{T_{\text {end }}}(f-50)^{2} \mathrm{dt}$

The load outage frequency is determined by solving this optimization problem. Load entering is determined by MGCC. In contrast to load shedding, the centralized controlling for entering loads can be effective because in second condition there is enough time for decision making in a central controller and distributing the control signal in the whole grid. In this paper the larger loads have larger priority to connect to the grid and load connecting procedure is started if the frequency deviation is less than $0.1 \mathrm{~Hz}$.

The MG is connected to the main grid and the main grid voltage and frequency dominates the behavior of the MG. after occurring a fault in the main grid the circuit breaker make the main grid and MG separate. This time is the reference of timing in this paper.

The ICA is used with the parameters as in table.2. 
Table2: the ICA parameters

\begin{tabular}{|c|c|}
\hline Number of Countries & 500 \\
\hline Number of empires & 50 \\
\hline Max iteration & 1000 \\
\hline$\zeta$ & 0.1 \\
\hline$\beta$ & 2 \\
\hline$\gamma$ & $0.5(\mathrm{rad})$ \\
\hline
\end{tabular}

The simulation results are shown in table. 3 and the time simulation result is shown in figure 6 .

Table 3: shedding frequency of each loads

\begin{tabular}{|c|c|c|}
\hline Load & Power $(\mathrm{kW})$ & Shedding frequency \\
\hline L7 & 20 & 49.35 \\
\hline L6 & 25 & 49.15 \\
\hline L4 & 30 & 49 \\
\hline L2 & 60 & - \\
\hline
\end{tabular}

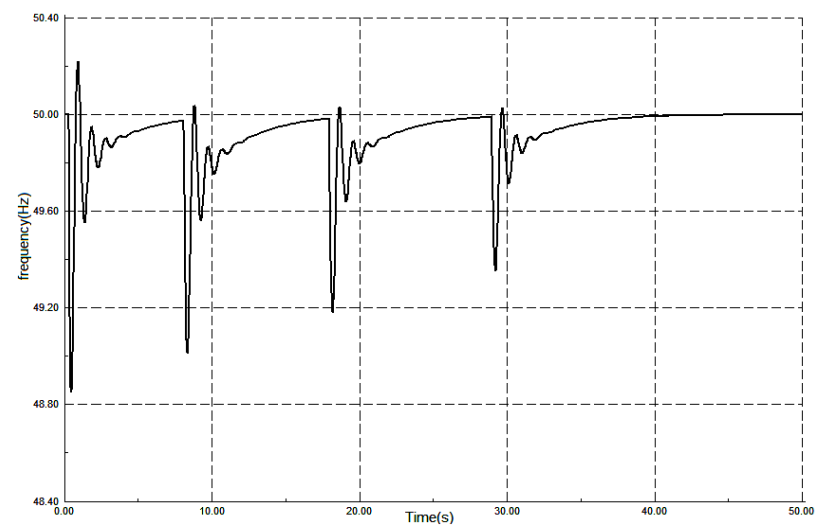

Fig.6: frequency deviation with load shedding during subsequent to $\mathrm{MG}$ islanding

Fig.6 shows that every load is shed when it is necessary to do so without any centralized system to gather data from across the system and send controlling signal to each load.

\section{Conclusion}

In this paper a novel approach to multi agent control in micro grid is presented. Omitting the MGCC in load shedding procedure leads to better frequency response of microgrid due to faster behavior of multi-agent systems. It is shown in this paper that every agent can play its role in stabilize the system that result the stability in the system.

\section{References:}

[1] Lasseter, R.; Piagi, P.: Providing premium power through distributed resources. Proc. 33rd Hawaii
International Conference on System Science, January 2000 .

[2] Lasseter, R.: Microgrids. IEEE PES Winter Meeting, 27- 31 January 2002, vol. 1, pp. 305-308.

[3] A. Peças Lopes, J.; Tomé Saraiva, J.; Hatziargyriou, N.; Jenkins, N.: Management of MicroGrids

[4] A. Peças Lopes, J.; L. Moreira, C.; G. Madureira, A.:Defining control strategies for MicroGrids islanded operation. IEEE Transactions on Power Systems, May 2006, vol. 21, no. 2, pp. 916-924.

[5] Piagi, P.; Lasseter, R.: Autonomous control of Microgrids. IEEE PES General Meeting, 18-22 June 2006.

[6] Pekka Wirtanen, "Simulation of the Management of a Micro Grid with Wind, Solar and Gas Generators", Master's Thesis for the degree of Master of Science in Engineering, Aalto University School of Science and Technology, October 2009.

[7] C. Lee, C. Chuang, C. Chu and P. Cheng, "Control Strategies for Distributed Energy Resources Interface Converters in the Low Voltage Microgrid," Proc. IEEE ECCE, 2009.

[8] E. Atashpaz, F. Hashemzadeh, R. Rajabioun, C. Lucas, "Colonial competitive algorithm: a novel approach for PID controller design in MIMO distillation column process", Intl. Journal of Intelligent Computing and Cybernetics, Vol.1, Issue 3, 2008, pp.337 - 355 .

[9] Ramin Rajabioun, E.Atashpaz, C.Lucas, "Colonial Competitive Algorithm as a Tool for Nash Equilibrium Point Achievement", Lecture Notes In Computer Science; Vol. 5073, Proc. of the Intl. conf. on Computational Science and Its Applications, Part II, 2008, pp.680-695.

[10] B.Oskouyi, E. Atashpaz-Gargari, N. Soltani, C. Lucas, "Application of Imperialist Competitive Algorithm for Materials Property Characterization from Sharp Indentation Test", to be appeared in International Journal of Engineering Simulation.

[11] A. Khabbazi, E. Atashpaz and C. Lucas, "Imperialist Competitive Algorithm for Minimum Bit Error Rate Beamforming", To be appeared in International Journal of Bio-Inspired Computation (IJBIC)

[12] A. M. Jasour, E. Atashpaz, C. Lucas, "Vehicle Fuzzy Controller Design Using Imperialist Competitive Algorithm", Second First Iranian Joint Congress on Fuzzy and Intelligent Systems, Tehran, Iran, 2008. 